\title{
Shun-ichi Amari awarded the 2019 Order of Culture
}

C Springer Nature Singapore Pte Ltd. 2019

His Majesty Emperor Naruhito conferred the Order of Culture, Japan's highest honor, on Shun-ichi Amari and five other people including this year's Nobel Prize Laureate in Chemistry Akira Yoshino. The ceremony was held in the Imperial Palace, Tokyo, on November 3, 2019. The Emperor handed the insignia of the order to each of them at the ceremony and congratulated them, praising their efforts, achievements and contributions to cultural advancement.

Shun-ichi Amari is Professor Emeritus of the University of Tokyo where he graduated in 1958, received his $\mathrm{PhD}$ in 1963 and was a full professor from 1981 to 1996. Professor Amari is famous for the creation of the discipline of information geometry and for his pioneering contributions to the neural network theory of brain function. He also made outstanding contributions for advancing science and technology in Japan especially as the Director of the RIKEN Brain Science Institute between 2003 and 2008.

Professor Amari has been one of the Honorary Editors of Information Geometry from the launch of the journal in 2017.

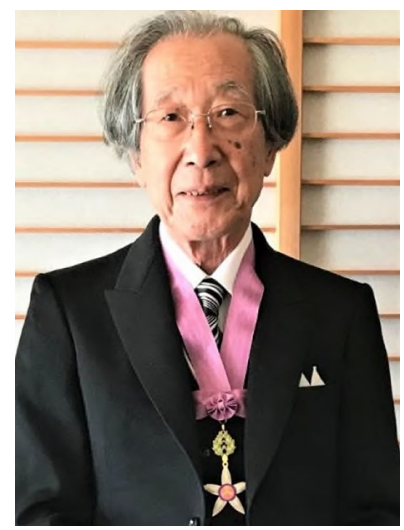

Professor Shun-ichi Amari with the insignia of the Order of Culture, Japan's highest honor.

The Editors, The Publisher 